\title{
Producción científica de la Revista "Pediatría" [Pediatr. (Asunción)]
}

\section{Scientific production of the Journal "Pediatría" [Pediatr. (Asunción)]}

\author{
Iván Barrios ${ }^{1}\left(\mathbb{0}\right.$, Rodrigo Navarro $^{2}\left(\mathbb{0}\right.$, Julio Torales $^{2}(0)$ \\ ${ }^{1}$ Universidad Nacional de Asunción, Facultad de Ciencias Exactas y Naturales, Carrera de Matemática \\ Estadística. San Lorenzo, Paraguay. \\ ${ }^{2}$ Universidad Nacional de Asunción, Facultad de Ciencias Médicas, Departamento de Psiquiatría de la \\ Infancia y la Adolescencia. San Lorenzo, Paraguay.
}

Señora Editora:

Los estudios bibliométricos analizan los artículos científicos de forma cualitativa y cuantitativa, al tiempo que miden la productividad y visibilidad de las revistas en la que estos se publican ${ }^{(1)}$. Los estudios bibliométricos representan medidas válidas para evaluar el nivel de producción científica de las publicaciones periódicas y son herramientas importantes para el desarrollo de las revistas científicas $^{(1,2)}$.

La Revista "Pediatría" [Pediatr. (Asunción)] es una revista científica revisada por pares y de acceso gratuito. Su objetivo principal es promover la realización, publicación y difusión en Paraguay de trabajos científicos de los profesionales de la salud del área pediátrica y difundir las experiencias de la medicina curativa, preventiva y social de la infancia. Se encuentra indexada en diversas bases de datos, entre las que destacan Web of Science, LILACS y Scielo Paraguay.

Las revistas científicas deben ser sometidas permanentemente a procesos de evaluación, para que tengan un verdadero valor en la difusión de los trabajos científicos de los investigadores y que, a su vez, más autores tomen conciencia de este valor y decidan enviar sus aportes a las revistas más reconocidas ${ }^{(3,4)}$.

Tomando en cuenta lo anterior, el objetivo de quiénes escribimos esta carta fue medir la productividad de la revista Pediatr. (Asunción), a través de indicadores cienciométricos ofrecidos por el programa Publish or Perish ${ }^{(5)}$. Este software es gratuito y recupera las citas de fuentes de datos (proveídos por Google Académico), calculando así los indicadores más habituales como son el índice-h, el número total de trabajos publicados, entre otros ${ }^{(6)}$.

La estrategia de búsqueda de índices se realizó utilizando el ISSN de la revista Pediatr. (Asunción). Los indicadores proporcionados por Publish or Perish incluyeron: número de artículos, citas totales, citas anuales, citas por artículo, índice $\mathrm{H}$ y autor de cada artículo $^{(6)}$. Se investigó el período incluido entre los años 2015 y 2020.

Se encontraron 129 artículos y un total de 449 citas. El promedio de citas por año es de 89,8 y el promedio de citas por artículo, de 1,16. El índice $\mathrm{H}$ de la revista es de 9 , lo que significa que existen por lo menos 9 artículos con un mínimo de $9 \operatorname{citas}^{(7)}$. En la tabla 1 se

Correspondencia:Julio Torales Correo:jtorales@med.una.py

Recibido: 23/01/2021 Aprobado: 08/03/2021

DOI: https://doi.org/10.31698/ped.48022021002

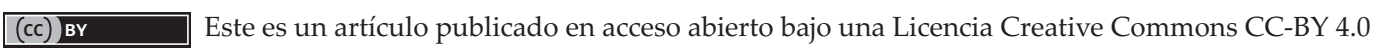


presentan los artículos con más citas, publicados entre los años 2015-2020. 5 de los 9 artículos más citados corresponden a artículos originales.

Tabla 1. Artículos con más citas publicados en Pediatr. (Asunción), periodo 2015-2020.

\begin{tabular}{|c|c|c|c|}
\hline Citas & Autor (es) & Título & Año \\
\hline 25 & Cardozo \& Samudio $^{(8)}$ & $\begin{array}{c}\text { Factores predisponentes y } \\
\text { consecuencias de la parasitosis } \\
\text { intestinal en escolares paraguayos }\end{array}$ & 2017 \\
\hline 17 & Mesquita \& Casartelli ${ }^{(9)}$ & $\begin{array}{l}\text { Hiperbilirrubinemia neonatal, } \\
\text { encefalopatía bilirrubínica aguda y } \\
\text { Kernicterus: La secuencia sigue } \\
\text { vigente en el siglo XXI }\end{array}$ & 2017 \\
\hline 17 & Jacquett \& Samudio ${ }^{(10)}$ & $\begin{array}{l}\text { Prevalencia de caries en dentición } \\
\text { temporal en niños de } 1 \text { a } 5 \text { años de } \\
\text { acuerdo a los criterios ICDAS en el } \\
\text { puesto de salud San Miguel de San } \\
\text { Lorenzo, Paraguay }\end{array}$ & 2015 \\
\hline 16 & $\begin{array}{c}\text { Ferreira Gaona, Diaz Reissner, } \\
\text { Pérez Bejarano, Sanabria Vázquez, } \\
\text { Alvarenga Rodas, Bazán Cohene, et } \\
\text { al } l^{(11)}\end{array}$ & $\begin{array}{l}\text { Salud bucal en preescolares y nivel } \\
\text { de conocimiento sobre higiene } \\
\text { bucal de sus madres, en escuelas } \\
\text { públicas y privadas de San } \\
\text { Lorenzo, Paraguay }\end{array}$ & 2016 \\
\hline 16 & $\begin{array}{l}\text { Ortiz Cuquejo, Aguiar, Samudio } \\
\text { Domínguez \& Troche Hermosilla }\end{array}$ & $\begin{array}{l}\text { Trastornos de la conducta } \\
\text { alimentaria en adolescentes: ¿una } \\
\text { patología en auge? }\end{array}$ & 2017 \\
\hline 16 & $\begin{array}{l}\text { Morínigo Isla, Sánchez Bernal, } \\
\text { Sispanov Pankow, Rolón Villalba, } \\
\text { Bonzi Arévalos, Medina, et al }{ }^{(13)}\end{array}$ & $\begin{array}{c}\text { Perfil nutricional por } \\
\text { antropometría de niños/as menores } \\
\text { de } 5 \text { años del sistema público de } \\
\text { salud, } 2013\end{array}$ & 2015 \\
\hline 16 & $\begin{array}{c}\text { Rolón, Fonseca, Genes, Pereira, } \\
\text { Zapatta \& Benítez }{ }^{(14)}\end{array}$ & $\begin{array}{l}\text { Chikungunya adquirida en Recién } \\
\text { Nacidos. Reporte de caso }\end{array}$ & 2015 \\
\hline 11 & Real Aparicio \& Arias Yrazusta ${ }^{(15)}$ & $\begin{array}{l}\text { Factores de riesgo asociados a la } \\
\text { hipoglicemia en neonatos de riesgo }\end{array}$ & 2016 \\
\hline 9 & $\begin{array}{l}\text { Iramain, Jara, Coronel, Cardozo, } \\
\text { Bogado, Morínigo \& López-Herce }{ }^{(16)}\end{array}$ & $\begin{array}{l}\text { Tratamiento con solución salina } \\
\text { hipertónica en lactantes } \\
\text { hospitalizados con bronquiolitis } \\
\text { aguda }\end{array}$ & 2016 \\
\hline
\end{tabular}


El análisis de una publicación periódica a través de indicadores cienciométricos permite observar las tendencias que sigue la revista. Además, los datos que se obtienen y las conclusiones a las que se arriban pueden ayudar a mejorar su gestión, facilitando la toma de decisiones editoriales ${ }^{(17)}$.

Los indicadores cienciométricos de la revista Pediatr. (Asunción) encontrados podrían servir como punto de partida para la consolidación continua del proceso editorial de la revista, en el camino de convertirse en un ejemplo de la calidad científica del país y de América Latina.

\section{Contribuciones de autoría}

\section{Iván Barrios:}

Concepción de la idea de estudio, búsqueda de datos, redacción del borrador, aprobación final del manuscrito.

\section{Rodrigo Navarro:}

Concepción de la idea de estudio, búsqueda de datos, revisión crítica de manuscrito, aprobación final del manuscrito.

\section{Julio Torales:}

Concepción de la idea de estudio, búsqueda de datos, revisión crítica de manuscrito, aprobación final del manuscrito.

\section{REFERENCIAS}

1. Gallardo Sánchez Y, Gallardo Arzuaga RL, Fonseca Arias M, Pérez Atencio ME. Scientometric characterization of Medwave's scientific production 2010-2014. Medwave. 2016;16(8):e6538. doi: https://doi.org/10.5867/medwa ve.2016.08.6538

2. Morales Fernández T, Martínez Ramos AT, Rivas Corrías B, Diago Gómez A, Clavero Fleites L, Martínez Bernal S. Producción científica de la revista EDUMECENTRO y su visibilidad a través de Google Académico. EDUMECENTRO [Internet]. 2017[Citado 10 Ene 2021];9(4):162-179. Disponible en: http://scielo.sld.cu/scielo. php?script=sci_arttext\&pid=S2077-28742017000400012

3. Arencibia-Arrebola DF, Betancourt-López V, GonzálezAlfalla N, Puig-Fernández Y, Biart-La Rosa O, FernándezSanguinety DF, et al. Estudio bibliométrico de la producción científica de VacciMonitor (2000-2013). VacciMonitor [Internet]. 2014[Citado 10 Ene 2021];23(2):4148. Disponible en: http://scielo.sld.cu/scielo.php?script =sci_arttext\&pid=S1025-028X2014000200002

4. Benet Rodríguez M, Morejón Giraldoni A. Posicionamiento de las revistas científicas de la salud en Cuba según el índice H5 obtenido del Google Scholar Metrics. Medisur [Inernet]. 2016[Citado 12 Ene 2021];14(2):180-188. Disponible en: http://scielo.sld.cu/ scielo.php?script=sci_arttext\&pid=S1727-897X201600 0200012\&lng=es\&nrm=iso\&tlng=es.

5. Ladouceur R. Publish or perish. Can Fam Physician [En línea]. 2019[Citado 16 Ene 2021];65(2):86. Disponible en:

https://www.ncbi.nlm.nih.gov/pmc/articles/PMC6515488 6. Harzing AW. Publish or perish[En línea]. 2020 [citado 22 Ene 2021]. Disponible en: https://harzing.com/resour ces/publish-or-perish

7. Dinis-Oliveira RJ. The H-index in Life and Health Sciences: Advantages, Drawbacks and Challenging Opportunities. Curr Drug Res Rev. 2019;11(2):82-84. doi: https://doi.org/10.2174/258997751102191111141801

8. Cardozo G, Samudio M. Factores predisponentes y consecuencias de la parasitosis intestinal en escolares paraguayos. Pediatr. (Asunción). 2017;44(2):117-125. doi: https://doi.org/10.18004/ped.2017.agosto.117-125

9. Mesquita M, Casartelli M. Hiperbilirrubinemia neonatal, encefalopatía bilirrubínica aguda y Kernicterus: La secuencia sigue vigente en el siglo XXI. Pediatr. (Asunción). 2017;44(2):153-158. doi: https://doi.org/10.18 004/ped.2017.agosto.153-158

10. Jacquett Toledo NL, Samudio M. Prevalencia de caries en dentición temporal en niños de 1 a 5 años de acuerdo a los criterios ICDAS en el puesto de salud San Miguel de San Lorenzo, Paraguay. Pediatr. (Asunción). 2015;42(3):216-224. doi: https://doi.org/10.18004/ped.20 15.diciembre.216-224

11. Ferreira Gaona MI, Diaz Reissner CV, Pérez Bejarano NM, Sanabria Vázquez DA, Alvarenga Rodas MV, Bazán Cohene DD, et al. Salud bucal en preescolares y nivel de conocimiento sobre higiene bucal de sus madres, en 
escuelas públicas y privadas de San Lorenzo, Paraguay. Pediatr. (Asunción). 2016;43(2):129-136. doi: https://doi.org/10.18004/ped.2016.agosto.129-136

12. Ortiz Cuquejo LM, Aguiar C, Samudio Domínguez GC, Troche Hermosilla A. Trastornos de la conducta alimentaria en adolescentes: una patología en auge? Pediatr. (Asunción). 2017;44(1):37-42. doi: https://doi.org/ 10.18004/ped.2017.abril.37-42

13. Morínigo Isla G, Sánchez Bernal S, Sispanov Pankow V, Rolón Villalba G, Bonzi Arévalos C, Medina H, et al. Perfil nutricional por antropometría de niños/as menores de 5 años del sistema público de salud, 2013. Pediatr. (Asunción). 2015;42(3):87-191. doi: https://doi.org/10.18 004/ped.2015.diciembre.187-191

14. Rolón P, Fonseca R, Genes L, Pereira S, Zapatta L, Benítez G. Chikungunya adquirida en Recién Nacidos. Reporte de caso. Pediatr. (Asunción). 2015;42(1):42-47. doi: https://doi.org/10.18004/ped.2015.abril.42-47
15. Real Aparicio CM, Arias Yrazusta P. Factores de riesgo asociados a la hipoglicemia en neonatos de riesgo. Pediatr. (Asunción). 2016;43(3):213-219. doi: https://doi.org/10.18 004/ped.2016.diciembre.213-219

16. Iramain R, Jara A, Coronel J, Cardozo L, Bogado N, Morinigo $\mathrm{R}$, et al. Tratamiento con solución salina hipertónica en lactantes hospitalizados con bronquiolitis aguda. Pediatr. (Asunción). 2016;43(1):45-51. doi: https://doi.org/10.18004/ped.2016.abril.45-51

17. Corrales-Reyes I, Fornaris-Cedeño Y, Reyes-Pérez J, Valdés-Gamboa L. Aproximación cienciométrica a la producción científica de Medisur. Medisur. [En línea] 2017[Citado 17 Ene 2021];15(5):640-646. Disponible en: http://www.medisur.sld.cu/index.php/medisur/article/vi ew/3554 